\title{
O cloze como indicador do desenvolvimento linguístico e da representação emergente do português brasileiro
}

\author{
Lia Abrantes Antunes SOARES (D) \\ Universidade Federal do Rio de Janeiro (UFRJ)
}

\section{○}

OPEN ACCESS

EDITADO POR

- Luiz Amaral (UMASS)

- Ricardo de Souza (UFMG)

- Thaís Maíra de Sá (CEFET-MG)

AVALIADO POR

- Cláudia Vieira (UFMG)

- Larissa Ciríaco (UFMG)

DATAS

- Recebido: 30/10/2020

- Aceito: 30/11/2020

- Publicado: 23/12/2020

\section{COMO CITAR}

Soares, L. A. A. (2020)

o cloze como indicador do desenvolvimento linguístico e da representação emergente do português brasileiro. Revista da Abralin, v. 19, n. 3, p. 880-908, 2020.
RESUMO

Estudos com análise da produção escrita de surdos crianças e adultos mostram evidências que compõem aqui um complexo quadro de ideias e hipóteses sobre a representação do PB emergente nessa população. Nossas investigações, fundamentadas em pressupostos sociocognitivistas da Linguística Cognitivo-Funcional (BYBEE, 2016; GOLDBERG, 2006; 2019; TOMASELLO, 2003), têm indicado que o componente morfossintático acumula grande parte das divergências materializadas em textos desses aprendizes. Embora divergências no uso de L2 sejam esperadas, chama atenção a pouca diferença na reorganização do conhecimento linguístico que se espera mutável ao longo de anos de escolarização e de contato com o PB escrito. As investigações centradas na produção têm recebido maior atenção dos estudos nas áreas da linguística e da educação de surdos. A habilidade de leitura, no entanto, não parece receber a mesma atenção. Questão que se levanta é se a atividade leitora também seria comprometida pelas divergentes combinações de itens lexicais e gramaticais, que parecem integrar o conhecimento linguístico desses aprendizes, a julgar por seus textos produzidos com muitas divergências morfossintáticas que comprometem os sentidos. O objetivo deste artigo é oferecer evidências sobre o desenvolvimento linguístico de aprendizes surdos universitários, que permitam caracterizar a representação cognitiva de construções nominais. Como resultado da análise de dois instrumentos em formato de Cloze adaptado, aplicados a 24 participantes, este artigo apresenta uma 


\section{REVISTA DA ABRALIN}

tipologia de esquemas nominais que parece integrar um sistema de competidores (SOARES, 2018). Esperamos que nossos resultados possam contribuir para uma didática aquisicional para surdos, com melhor aproveitamento do input escrito.

\section{ABSTRACT}

Studies analyzing the written production of deaf children and adults show evidence that compose our complex picture of ideas and hypotheses about the representation of the emerging BP in this population. Our investigations, based on socio-cognitive assumptions of Cognitive-Functional Linguistics (BYBEE, 2016; GOLDBERG, 2006; 2019; TOMASELLO, 2003), have indicated that the morphosyntactic component accumulates a large part of the divergences materialized in these learners' texts. Although divergences in the use of L2 are expected, it is noteworthy that there is little difference in the reorganization of linguistic knowledge that is expected to change, between children and adults, over years of schooling and contact with written BP. Research focused on production has received greater attention from studies in the areas of linguistics and education of the deaf. Reading skills, however, do not seem to receive the same attention. The question that arises is whether the reading activity would also be compromised by the divergent combinations of lexical and grammatical items, which seem to integrate the linguistic knowledge of these learners, judging by their written texts that show many morphosyntactic divergences that compromise the reader's understanding. The purpose of this article is to offer evidence on the linguistic development of deaf university students, which allows to characterize the cognitive representation of nominal constructions. As a result of the analysis of two instruments in an adapted Cloze format, applied to 24 participants, this article presents a typology of nominal schemes that seems to integrate a system of competitors (SOARES, 2018). We hope that our results can contribute to an acquisitional didactic for the deaf, with better use of written input.

\section{PALAVRAS-CHAVE}

Aprendizes surdos. Cloze. Analogização. Representação do PB.

Sociocognitivismo.

\section{KEYWORDS}

Deaf learners. Cloze. Analogization. PB representation. Sociocognitivism. 


\section{REVISTA DA ABRALIN}

\section{Introdução}

Dentre as duas habilidades linguísticas de que a escolarização de surdos deve se ocupar - ler e escrever -, parece que as atividades de produção escrita são mais exploradas em pesquisas científicas, assim como em práticas de ensino e em modelos de avaliação. Problematizando a questão, proponho breve reflexão a seguir, a fim de situar o leitor a respeito do estagnado cenário em que se encontram práticas de ensino do PB para surdos.

Pode-se questionar se a habilidade de leitura na L2 recebe a recomendada atenção da escola, considerando que seu desenvolvimento é a forma primária para recepção de input pelos aprendizes surdos. Se as únicas práticas com o input linguístico do PB se apresentam interpretadas/traduzidas para LIBRAS, as necessárias atividades de leitura não funcionam como uma fonte para percepção dos usos de construções linguísticas que se combinam em sequência não aleatória para significarem. Inclusive, as avalições oficiais em formato traduzido para LIBRAS parecem uma alternativa consequente de um trabalho escolar que não se volta para o desenvolvimento da habilidade leitora, fundamental para emergência do complexo sistema da L2 e consequente desenvolvimento da autonomia leitora.

A menor atenção ao trabalho local e global com input do PB fortalece a decisão pela tradução para LIBRAS, dos enunciados e dos textos que compõem avaliações, como, por exemplo, a proposta de redação do Exame Nacional do Ensino Médio - ENEM, não havendo, portanto, avaliação da habilidade leitora em PB. É coerente considerar que, se a escola não se ocupa do desenvolvimento de uma dada habilidade, também não deve apoiar ou recomendar sua avaliação.

Outro dado importante, recentemente abordado em Costa et al. (2020), é a relação de indicadores de níveis de leitura que aprendizes surdos alcançam ao final da educação básica. Andrews et al. (2015), corroborando indicação de pesquisas revisadas por Bochner e Albertini (1988), verificam que o nível médio de capacidade leitora em inglês, alcançado por surdos adultos americanos, é semelhante ao esperado para o $4^{\circ}$ ano de escolarização. Possivelmente, a média referente aos surdos brasileiros não seja muito diferente. Essa média sugere mais uma evidência de um trabalho menos focado na recepção do input escrito na L2, absolutamente necessário e poderoso para identificação do funcionamento das bases morfossintática e semântico-discursiva de um sistema linguístico, que afeta, consequentemente, a produção.

Com vistas à necessária autonomia leitora de aprendizes surdos, seria esperado mais destaque a práticas de leitura que abordem, por exemplo, a observação das escolhas e combinações lexicais mais e menos idiomáticas (formulaicas) que materializam sentidos em PB. Com menor atenção, ainda que não intencional, ao desenvolvimento da habilidade de leitura, por meio da qual é possível encontrar padrões construcionais em pareamentos forma/sentido no input da L2, efeitos negativos se observam na produção escrita de aprendizes em todos os níveis de escolaridade.

Buscar entender como os aprendizes de L2 adquirem, representam e usam o conhecimento linguístico é essencial para a construção de uma didática aquisicional. Por uma perspectiva sociocognitivista (TOMASELLO, 2003), a emergência de língua se dá por um processo da experiência para a abstração, em um movimento que forma, reforça e reforma suas representações cognitivas. Ou seja, 


\section{REVISTA DA ABRALIN}

a exposição ao input linguístico é absolutamente necessária para que, por meio de atividades de leitura que promovem percepção de padrões com forma e sentido, seja possível a expressão compreensível via escrita. Até o momento, esse tem se mostrado ser um percurso eficiente para aprendizagem de línguas.

Feitas as considerações iniciais que localizam o contexto desta pesquisa ${ }^{1}$, nas próximas seções apresento referencial teórico e metodologia que se utiliza da técnica Cloze para coleta de informações que evidenciem a representação cognitiva das construções nominais do PB. A análise dos preenchimentos resultou em uma proposta de tipologia de construções nominais que parecem caracterizar a representação do complexo sistema bilíngue usado por aprendizes surdos.

\section{Referencial teórico}

Este estudo tem orientação da Linguística Funcional-Cognitiva (LFC), vertente que abarca modelos teóricos cuja interface uso-cognição é privilegiada (BARLOW; KEMMER, 2000; BYBEE, 2016; GOLDBERG, 2006; 2019; HILPERT, 2019). Caracteriza essa vertente o pressuposto de que a experiência com a língua molda constantemente o conhecimento do falante, organizado em construções léxicogramaticais que emergem sob a atuação de processos cognitivos de domínio geral.

As investigações, pelo viés da LFC e com alvo nas produções escritas, têm gerado publicações de cunho descritivo e explicativo sobre o desempenho linguístico de aprendizes surdos sinalizantes de LIBRAS, adultos e crianças (FREITAS et al., 2018; NASCIMENTO et al., 2919; 2020). As análises das atividades escritas por esses aprendizes evidenciam inconsistências em diferentes níveis e domínios que constituem o português brasileiro (PB).

Considerando que o conhecimento linguístico de uma L2 não evolui sem ligações com o conhecimento de outras línguas já adquiridas, principalmente da L1, investigações apoiadas em modelos teóricos convergentes com pressupostos cognitivo-funcionais apontam ocorrências motivadas principalmente por processos de analogização, em que se observam, por exemplo:

(i) transferência de padrões da LIBRAS, observável na forma de (a) apagamentos, principalmente de itens gramaticais [e.g. Meu curso $\emptyset$ Letras-Libras e $\emptyset 3$ periodo. (SOARES; NASCIMENTO, 2020], e (b) não distinção morfológica que caracteriza categorias gramaticais [e.g. Parabéns, querida melhor minha amiga que muito especial, sucesso, simpática, carinhosa (...). (Corpus NEIS/UFRJ);

(ii) supergeneralizações de padrões construcionais do PB, das quais emergem construções que até se combinam localmente, mas que, nos níveis sentencial e textual, produzem

\footnotetext{
${ }^{1}$ Este estudo traz um recorte de minha tese de doutorado, com recentes reflexões.
} 


\section{REVISTA DA ABRALIN}

inconsistentes usos com frágeis conexões combinatórias de itens que parecem deslizar por várias categorias, resultando em combinações incompatíveis [e.g. Eu estava conselho a vida com ele de principal procurando seja feliz e trabalho a vida sucesso cuide família pagamento o corsu] (Corpus NEIS/UFRJ)], em meio a outras que parecem já formar chunks, isto é, blocos entrincheirados frequentemente usados [seja feliz], mas que, sem mudança na morfologia do item verbal, [seja] não se combina com o item anterior [procurando (+ infinitivo)].

Esses exemplos são produtos de tarefas aplicadas em sala de aula, escritos por estudantes surdos universitários sinalizantes de LIBRAS. Em convergência com pressupostos do Modelo de Competição (BATES; MACWHINNEY, 1981), em estudos anteriores (SOARES, 2018; SOARES, 2020; SOARES; NASCIMENTO, 2020) com análise dessas e de outras produções, sugiro que parece haver um sistema de competidores em uso pelos aprendizes surdos, isto é, uma rede de exemplares competidores com forças variáveis, que se colocam em uma arena de uso. Algumas vezes, os competidores vencedores são consistentes com os usos do PB; outras vezes, os vencedores são consistentes com os usos da LIBRAS, ou, ainda, vence a competição uma combinação mesclada, com traços do PB e da LIBRAS. Esse sistema é gerado por experiências diferentes, dentre as quais estão as escolares.

O sistema de competidores se caracteriza, portanto, pela coexistência $(+/-$ conflitante ou +/convergente) de construções léxico-gramaticais das duas línguas, ou seja, unidades simbólicas que pareiam forma e sentido (cf. GOLDEBERG, 2006), modeladas pela experiência que aprendizes puderam ter com a L1 em uso. Tais experiências com a L1 e com a L2, que variam de indivíduo para indivíduo, têm se mostrado fator importante nos estudos em perspectiva sociocognitivista.

Quando se assume que a experiência do indivíduo com a língua é capaz de formar, reforçar e reformar seu repertório (sua gramática), uma implicação a esse pressuposto é a de que o repertório de cada indivíduo apresentará semelhanças, mas também diferenças, mesmo que sejam falantes/aprendizes das mesmas línguas. Essa implicação se aplica aos indivíduos aprendizes de L2, como mostram estudos de Höder (2018) e Hilpert (2019), com aprendizes ouvintes falantes de línguas orais, e de Soares (2018; 2020), Soares e Nascimento (2020), com aprendizes surdos falantes de línguas de sinais, com experiências familiares, sociais, educacionais e linguísticas muito diferentes, como é o caso dos participantes desta pesquisa, cujo perfil será descrito na próxima seção.

\section{Metodologia}

A escolha de um instrumento em formato de Cloze (texto lacunado) pareceu ser uma boa opção de atividade de leitura em que se poderia verificar a representação cognitiva de construções nominais que 


\section{REVISTA DA ABRALIN}

constituem o PB. O produto da leitura, observável via preenchimento escrito de lacunas, suscitou algumas perguntas, dentre as quais destacamos algumas que têm orientado nossa conduta metodológica:

- como aprendizes processam, armazenam e acessam construções +/- gramaticais/lexicais quando usam o PB em atividades de compreensão e de produção escritas?

- como eles identificam padrões de forma e significado no material escrito em PB, oferecido pela escola e/ou por seu entorno?

- o sistema linguístico usado por aprendizes surdos emerge exclusivamente da experiência com o input escrito ou de um input pouco e mal percebido pelo canal auditivo e/ou pelo visual, quando são submetidos à leitura labial ${ }^{2}$ ?

A fim de juntar evidências que contribuam para a composição de respostas a essas e a outras perguntas e, ainda, de tornar o experimento replicável a outros grupos de aprendizes, foi definida uma metodologia para obtenção, análise e discussão de dados do desempenho linguístico de aprendizes surdos universitários, com vistas a investigar a representação do conhecimento linguístico armazenado.

Nas próximas subseções, detalhamos o percurso metodológico para obtenção e análise do corpus construído com um total de 46 instrumentos aplicados, nos quais foram lacunados itens nominais, suprimindo morfemas indicadores das categorias gramaticais de substantivo e de adjetivo.

\subsection{O instrumento e sua composição}

O Cloze é uma das possíveis técnicas disponíveis para ensino, avaliação e pesquisa e tem sua validade, pertinência e praticidade demonstradas por estudos nacionais e internacionais. A técnica foi desenvolvida por Taylor (1953) para verificar leiturabilidade/inteligibilidade de um texto. Em sua proposta original, o Cloze tem a configuração de um texto lacunado a cada cinco palavras, cabendo ao leitor recuperar durante a leitura, por probabilidade combinatória de forma e sentido, a palavra exata que preenche a lacuna. Adaptações ao formato original foram propostas, tais como: aumento da razão de lacunamento para cada sétima ou nona palavra; omissão aleatória de até $20 \%$ das palavras do texto; indicação da primeira letra do item lacunado, ou ainda, definição do tipo de item lacunado, determinada pela escolha de uma dada categoria gramatical (adjetivo, substantivo, verbo, preposição etc.).

\footnotetext{
${ }^{2}$ Em Soares (2020), o leitor pode encontrar discussão sobre possíveis efeitos na representação cognitiva do input percebido via leitura labial.
} 


\section{REVISTA DA ABRALIN}

A técnica requer ativação de relações de forma e significado entre elementos do texto, assim como de associações entre conhecimento prévio e informação veiculada no texto. Tem sido usada para verificação de desempenho linguístico e leitor em primeira e em segunda línguas, como mostram trabalhos de Clarke e Burdell (1977), Abraham e Chapelle (1992), Santos et al. (2002), Joly et al. (2014), Santos e Monteiro (2016) e Abreu et al. (2017), dentre outros.

Santos e Monteiro (2016), por exemplo, revisam estudos que mostram a correlação entre o teste Cloze e outro instrumento - Escala de Avaliação da Escrita (EAVE) - aplicado para medir compreensão e produção escritas. Os achados desses estudos têm demonstrado a validade do Cloze enquanto técnica de avaliação da compreensão escrita e sua contribuição relativa à avaliação diagnóstica do desenvolvimento linguístico dos aprendizes, que possibilita ajustes no planejamento de atividades de ensino.

Diferente das aplicações em larga escala para avaliar níveis de leitura de aprendizes em diferentes níveis de escolarização, neste estudo, proponho sua aplicação como um instrumento para avaliação qualitativa do conhecimento linguístico de surdos que concluíram a educação básica e chegaram à universidade, a fim de oferecer descrição inicial que caracterize a representação cognitiva do PB em contato com a LIBRAS. Destacamos, ainda, que o Cloze pode ser aplicado ao ensino, como uma técnica que permite desenvolver percepção de padrões combinatórios da língua e suas restrições locais e contextuais, com potencial de apuração de mecanismos metacognitivos (consciência e monitoramento).

O Cloze exige do aprendiz acionamento de conhecimento linguístico e conceitual durante a execução da atividade leitora, portanto, como destacam Abraham e Chapelle (1992), a preparação do instrumento deve considerar níveis de dificuldade do texto, em relação tanto à temática abordada quanto ao item lacunado, compatíveis com o público-alvo. Essas duas indicações foram consideradas para a elaboração de dois instrumentos, conforme descrição a seguir.

A definição dos textos para compor os instrumentos exigiu atenção à familiaridade temática e à funcionalidade comunicativa. Consideramos tais aspectos ativadores de esquemas de representações mentais com saliência gradiente (de mais a menos saliente), recuperáveis pelos participantes, a depender de seu maior ou menor contato com variedades de textos. Tais aspectos podem minimizar ou aumentar efeitos negativos para compreensão leitora do texto e deixar proeminentes as variáveis lexicais e gramaticais da língua-alvo. A leitura de textos técnicos, por exemplo, exigiria do participante conhecimento de palavras e fórmulas pouco frequentes, o que comprometeria a inteligibilidade textual e os processos de inferência que poderiam ferir restrições linguístico-discursivas da língua-alvo.

A escolha dos textos, portanto, seguiu o critério principal de familiaridade temática gradual. Uma notícia com tema familiar foi o primeiro texto selecionado, a fim de controlar possível interferência negativa de um tema desconhecido que prejudicasse a compreensão leitora, impedindo o acesso à palavra que sofreu lacunamento parcial. A notícia traz informações sobre atletas surdos em competições esportivas das Paraolimpíadas, tema bastante comentado pelos participantes da pesquisa.

O segundo texto selecionado compõe um folheto com informações sobre um roteiro de livrarias do centro histórico do Rio de Janeiro. Por não apresentar tema familiar, mas, sim, de conhecimento geral, eleva, em alguma medida, o nível de compreensão leitora. Assim, com tal composição temática, procedemos à construção dos instrumentos Cloze, de forma a verificar, por meio da leitura e 


\title{
REVISTA DA ABRALIN
}

reconhecimento de palavras lacunadas, a representação abstrata do conhecimento linguístico do PB, mais especificamente, a representação das diferentes formas de constituição morfológica de itens de categoria nominal.

Antes do lacunamento, os textos passaram pelas lentes de uma ferramenta computacional de análise linguística: o programa WordSmith Tools, desenvolvido por Mike Scott, e publicado pela Oxford University Press. Sua versão 6.0 disponibiliza vários recursos importantes para análise de nossos dados, gerando maior confiabilidade às interpretações. Informações, tais como frequência de palavras e colocação, foram processadas pelo programa.

Da lista de itens ordenados por frequência de ocorrência, selecionamos as cinco palavras lexicais mais frequentes em cada texto, a saber: Brasil, bronze, história, primeira, atletas (texto 1) e livraria, Rio, centro, antiga, cidade (texto 2). Essa informação funciona como uma referência, não só para a orientação temática encontrada nos textos, mas também o quão conhecidas ou desconhecidas as palavras poderiam ser para os participantes da pesquisa. Avaliamos que a frequência de ocorrência de tais palavras seria um balizador inicial para manter a escolha dos textos, já que são passíveis de terem sido aprendidas durante a educação básica.

O lacunamento dos dois textos não teve nem seu distanciamento fixado em formato rígido (a cada 5, 7 ou 9 palavras) nem apagamento integral da palavra, como a proposta inicial de Taylor. Optamos por manter o radical - parte da palavra que carrega significado lexical mais saliente -, o que facilita o acesso ao item e torna a atividade leitora em L2 menos custosa, e lacunamos morfemas finais de nominais (substantivos e adjetivos) e de algumas formas verbais como itens distratores, a fim de evitar indução a categorias nominais. Os recortes a seguir ilustram os dois instrumentos em formato de Cloze.

\footnotetext{
Brasil faz história com a primeira medalha de ouro nas Surdolimpíadas

- Ser recordista olímpico e mund___- é um sonho desde menin____. Hoje, agradeço a todos que fize ____ e fazem parte dele. Trabalh____ duro todos esses anos. Um agradeci_____ especial a minha mãe, Andrea, pois sem ela nada ter____ se concretizado - disse Guilherme em uma public____ nas redes sociais, logo após a prova.

(Recorte do instrumento 1, disponível em https://oglobo.globo.com/esportes/)
}

\begin{abstract}
Rio da história, Rio de maravilhas
Temos o prazer de apresentar a $4^{\mathrm{a}}$ edição do Roteiro das Livrarias do Centro Histórico do Rio de Janeiro. São 53 livr_____ com as respectivas especi____, para facilitar a busca dos leit____. Afinal, para atender à vari____ produção editorial brasi_____, são necessárias muitas livr___-_, de todos os tipos. E isso você encontra aqui, anda____ a pé no Centro da Cidade Maravilh_

(Recorte do instrumento 2, publicado no Roteiro das Livrarias do Centro Histórico do Rio de Janeiro, $4^{\mathrm{a}}$ ed. AEL/RJ - Associação Estadual de Livrarias do Rio de Janeiro, 2012.)
\end{abstract}

Os recortes ilustram o formato de Cloze facilitado, com lacunamento parcial dos itens. Esse formato nos pareceu uma alternativa viável para, por meio da leitura, buscar evidências sobre a 


\section{REVISTA DA ABRALIN}

representação cognitiva de construções nominais do PB usado pelos participantes surdos. Dessa forma, indicações sobre consciência do funcionamento do PB podem ser verificadas.

Além do formato, a extensão dos textos foi controlada. O primeiro instrumento (INST 1) totaliza 331 itens (tokens) e 184 formas (types); o segundo (INST 2) totaliza 310 itens (tokens) e 190 formas (types). Essas informações derivam percentuais - 58\% e 62\% -, relativos à razão entre itens e formas que revelam a riqueza lexical de um texto. Quanto maior o valor encontrado pelo programa de análise lexical, mais palavras diferentes terá o texto, por isso, atentamos para o número de palavras diferentes que compõe os dois textos. Procuramos equilíbrio entre a riqueza de formas a serem testadas em suas combinações no texto e a possibilidade de maior dificuldade que tal riqueza poderia oferecer para a compreensão leitora de aprendizes com níveis diferentes de proficiência. Controlamos, portanto, tais variáveis para que os instrumentos tivessem configuração semelhante.

Mais do que mensurar compreensão leitora de um texto em L2, entendemos que a técnica do Cloze oferece informações a respeito dos padrões linguísticos que o aprendiz já adquiriu (preenchimentos convergentes) e os que ainda não (preenchimentos divergentes). Nossa hipótese é que espaços em branco e preenchimentos divergentes pela quebra de alguma restrição morfossintática ou semântico-discursiva podem revelar um tipo de informação cuja análise seguiu etapas descritas na próxima seção.

\subsection{Perfil dos participantes}

Neste artigo, as amostras analisadas são de grupos de universitários surdos usuários de LIBRAS com diferentes perfis: o tipo de surdez; a idade da perda auditiva e do início de aquisição de linguagem; a relação com comunidades de fala (família e escola) e a relação entre os canais perceptuais e as experiências linguísticas. Esses aspectos foram contemplados em um formulário apresentado aos participantes da pesquisa, a partir do qual definimos o perfil dos grupos, com o propósito de verificar potenciais efeitos das condições tardia ou precoce de aquisição de linguagem, experimentadas pela população surda. 


\section{REVISTA DA ABRALIN}

\begin{tabular}{|c|c|c|c|}
\hline & \multicolumn{2}{|c|}{ Surdos de primeira geração } & \multirow[b]{2}{*}{$\begin{array}{l}\text { Aprendizagem tardia da } \\
\text { LIBRAS. }\end{array}$} \\
\hline $\begin{array}{l}\text { A1 } \\
9 \text { participantes }\end{array}$ & $\begin{array}{l}\text { Surdez severa ou pro- } \\
\text { funda; congênita ou ad- } \\
\text { quirida até } 2 \text { anos; }\end{array}$ & $\begin{array}{l}\text { Acompanhamento fono- } \\
\text { audiológico precoce, } \\
\text { com duração média de } 14 \\
\text { anos; }\end{array}$ & \\
\hline $\begin{array}{l}\text { A2 } \\
9 \text { participantes }\end{array}$ & $\begin{array}{l}\text { Surdez severa ou pro- } \\
\text { funda; congênita ou ad- } \\
\text { quirida até } 2 \text { anos; }\end{array}$ & $\begin{array}{l}\text { Acompanhamento fono- } \\
\text { audiológico iniciado em } \\
\text { idade escolar, com dura- } \\
\text { ção média de } 9 \text { anos; }\end{array}$ & $\begin{array}{lr}\text { Aprendizagem } & \text { da } \\
\text { LIBRAS iniciada em } \\
\text { idade escolar. }\end{array}$ \\
\hline \multirow[t]{2}{*}{$\begin{array}{l}\text { A3 } \\
2 \text { participantes }\end{array}$} & $\begin{array}{l}\text { Surdez profunda congê- } \\
\text { nita; }\end{array}$ & $\begin{array}{l}\text { Sem acompanhamento } \\
\text { fonoaudiológico; }\end{array}$ & $\begin{array}{l}\text { Aprendizagem tardia da } \\
\text { LIBRAS. }\end{array}$ \\
\hline & GRUPO B & los de segunda geração & \\
\hline \multirow[t]{2}{*}{2 participantes } & Surdez congênita; & $\begin{array}{l}\text { Acompanhamento fono- } \\
\text { audiológico iniciado em } \\
\text { idade pré-escolar; }\end{array}$ & $\begin{array}{l}\text { Com exposição natural à } \\
\text { L1 sinalizada. }\end{array}$ \\
\hline & GRUPO C & los com PBL1 & \\
\hline 2 participantes & $\begin{array}{l}\text { Surdez severa ou pro- } \\
\text { funda adquirida entre } 5 \mathrm{e} \\
7 \text { anos; }\end{array}$ & $\begin{array}{l}\text { Acompanhamento fono- } \\
\text { audiológico; }\end{array}$ & $\begin{array}{l}\text { Aprendizagem tardia da } \\
\text { LIBRAS. }\end{array}$ \\
\hline
\end{tabular}

Os grupos são bastante heterogêneos tanto em termos de número de integrantes quanto em termos de características aquisicionais. Sendo assim, este estudo não se insere nos protocolos padronizados para análise estatística, tradicionalmente usados em avaliações em larga escala.

\subsection{Procedimentos}

Todos os participantes preencheram um formulário com informações sobre seu perfil; assinaram um Termo de Consentimento Livre e Esclarecido e receberam instruções em LIBRAS sobre sua participação na pesquisa. A aplicação dos dois instrumentos Cloze foi agendada com grupos de informantes ou individualmente, realizada em sala de aula e não teve seu tempo controlado. Os dois informantes surdos de segunda geração (grupo B) não participaram da aplicação do INST 2.

Para verificação da legibilidade do instrumento e testagem da recuperação dos itens lacunados, uma aplicação prévia foi realizada com 11 participantes ouvintes, estudantes universitários do curso de Letras, com idade média de 25 anos, cuja função de grupo controle se fez necessária. Esse procedimento com um grupo controle observou informações relativas ao nível de dificuldade dos textos, 


\section{REVISTA DA ABRALIN}

que poderia impedir sua leitura, mesmo para um nativo do PB. Dessa forma, buscamos aumentar o grau de confiabilidade do experimento.

\subsection{Etapas para observação dos dados}

Este estudo de natureza qualitativa exige cumprimento de etapas que envolvem a investigação do objeto linguístico-cognitivo, quais sejam:

- verificação do (não)reconhecimento dos itens nominais via atividade de leitura;

- $\quad$ identificação de preenchimentos convergentes e divergentes;

- classificação dos tipos de divergências, a fim de evidenciar tendências;

- $\quad$ descrição das ocorrências coletadas;

- explicação para os aspectos que podem ter motivado ocorrências divergentes;

- $\quad$ avaliação da pertinência dos resultados obtidos com o Cloze adaptado.

Com base nesse percurso, buscamos meios de explicar, no âmbito da cognição e do uso, o comportamento de construções nominais parcialmente lacunadas e preenchidas (ou não) pelos informantes surdos durante a leitura de cada um dos dois textos.

Para a análise, são considerados 50 itens inseridos em 48 construções nominais (Quadro 2), analisados nos 46 instrumentos aplicados. Esses itens de categoria nominal (substantivos e adjetivos) sofreram lacunamento parcial, ou seja, lacunamento do morfema indicador de sua colocação da estrutura do sintagma nominal, sendo inaceitáveis, por exemplo, preenchimentos com morfemas de categoria verbal.

\begin{tabular}{|c|c|}
\hline Texto 1 (Notícia sobres as Surdolimpíadas) & Texto 2 (Roteiro de livrarias) \\
\hline 1- [o brasil_-_-_ Guilherme Maia] & 1- [53 livr__-_-_] \\
\hline 2- [o nada_-_-__] & 2- [muitas livr__-_-_] \\
\hline 3- [o novo recorde mund & $3-[$ ivr__-_-_ gerais $]$ \\
\hline 4- [a delegação brasil__-_-_] & 4- $\left[\right.$ livr $\_-----$religiosas $]$ \\
\hline 5- [99 atlet_-_-_- ] & 5- [livr__-__-_ especializadas $]$ \\
\hline 6- [quatro medalh__-_-_] & 6- [uma ideia, uma história, um pensa__-_-_] \\
\hline 7- [22 modalidades esport__-_-_] & 7- [a descob_____-_ $]$ \\
\hline
\end{tabular}




\section{REVISTA DA ABRALIN}

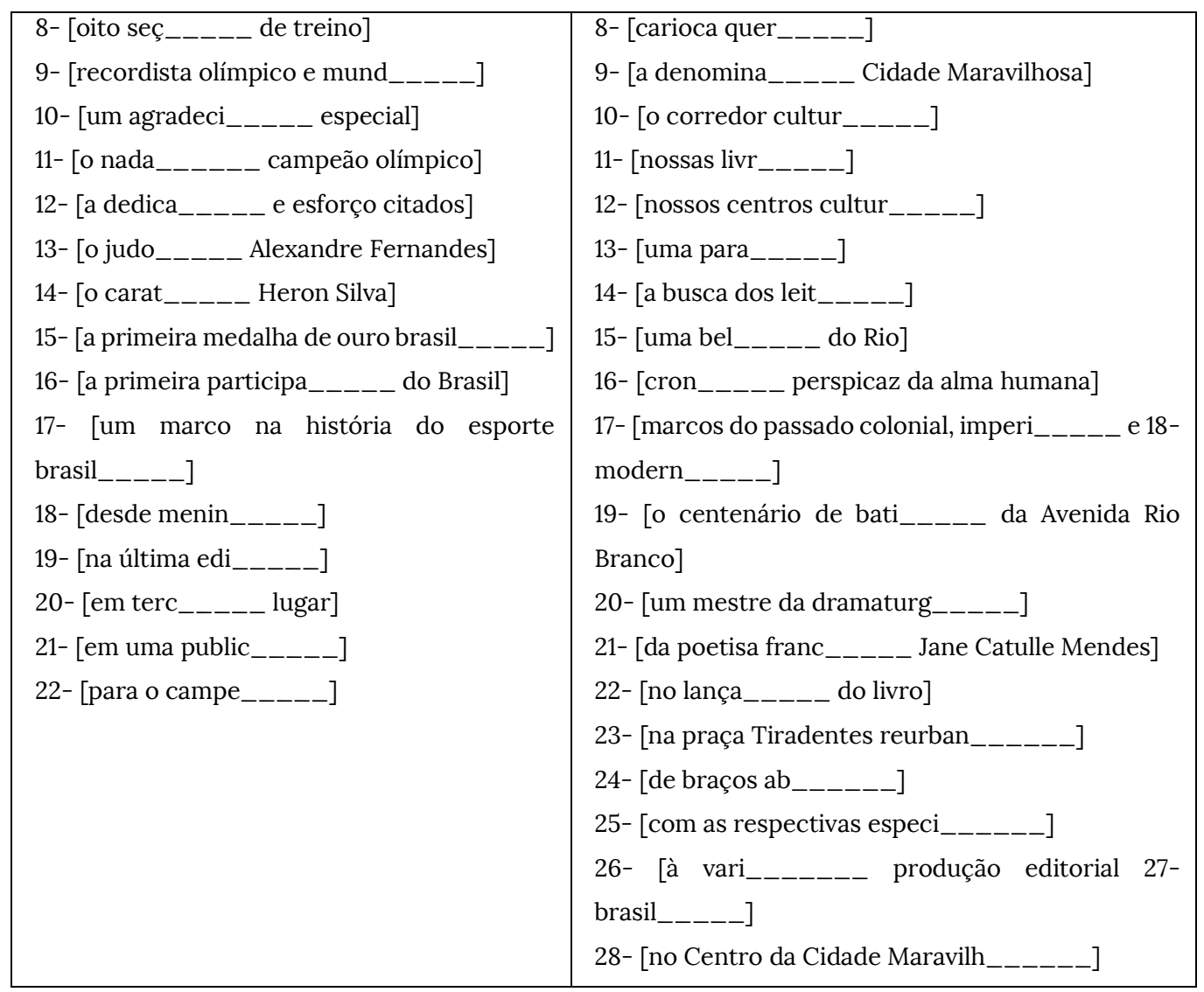

QUADRO 2 - Construções selecionadas nos dois textos

Fonte: Soares (2018).

Investigamos na próxima seção o que as ocorrências que compõem nossa amostra podem indicar sobre a organização cognitiva das construções do PB usadas pela população surda participante da pesquisa. Com o Cloze, esperamos obter evidências sobre a representação lexical e gramatical, isto é, o conhecimento linguístico armazenado, por meio do desempenho dos participantes na atividade leitora em PB. A análise dos dados observa (i) o conteúdo dos preenchimentos (forma e significado) e (ii) os processos de monitoramento ativados ou não para a escolha do preenchimento (consciência metacognitiva). A análise proposta é de cunho qualitativo e não serão apresentados resultados estatísticos.

\section{Análise e discussão dos dados}

Vários itens lacunados nas construções do Quadro 2 admitem mais de uma possibilidade de preenchimento, a depender dos constituintes adjacentes, internos à construção nominal, e externos a ela. Sendo assim, a análise dos preenchimentos escolhidos pelos participantes observa as restrições 


\section{REVISTA DA ABRALIN}

intra/inter lexicais e sentenciais e do contexto em que foram usados, a fim de que haja pareamento da forma escolhida (morfema nominalizador) e seu significado.

As construções em que se inserem os itens lacunados apresentam o padrão geral descrito em Castilho (2010): [(ESPECIFICADORES) + NÚCLEO + (COMPLEMENTADORES)], em que, quando o núcleo (N) for uma preposição, a posição de especificador (ESP) sempre se apresentará vazia, mas variará quando o $\mathrm{N}$ for um nome. Em relação aos complementadores (COMP), seus núcleos podem selecionar sintagmas adjetivais e preposicionais. Tomamos, assim, a construção esquemática [(ESP) $\mathrm{N}$ (COMP)] como unidade básica para análise dos preenchimentos, em razão de sua representação contemplar o contínuo do léxico para gramática, em uma interação com unidades específicas (morfemas) que oferecem evidências importantes sobre o repertório usado pelos aprendizes surdos.

Os instrumentos em formato de Cloze viabilizaram investigação sobre a relação entre leitura, conhecimento prévio e conhecimento do sistema linguístico usado pelos participantes surdos universitários. Analisamos o que promoveu e o que impediu a compreensão dos dois textos escritos em PB. Para tanto, partimos da premissa de que o produto da atividade leitora resulta da interação entre conhecimento textual, conhecimento de mundo e, sobretudo, conhecimento linguístico do leitor, sem o qual a atividade leitora não se inicia.

Nesse sentido, alcançar compreensão leitora na L2 prevê (i) acionamento de conhecimento prévio adquirido com a experiência e (ii) reconhecimento de palavras colocadas em construções da L2, com os quais se estabeleça uma relação que comporte coerência com os elementos dispostos no texto. Em um processo dinâmico, os participantes da pesquisa devem se apoiar nas palavras do texto combinadas em sequências não aleatórias e com algum grau de esquematicidade, a fim de processarem e inferirem informações, noções e conceitos evocados no texto. De outra forma, não se pode alcançar bom nível de compreensão leitora na língua-alvo.

Embora a análise quantitativa não seja central neste estudo, os preenchimentos foram contabilizados por grupo e geraram percentuais de preenchimentos convergentes para os dois instrumentos. A informação dos percentuais gerais é um indicador inicial do desempenho leitor dos participantes que compõem os grupos.

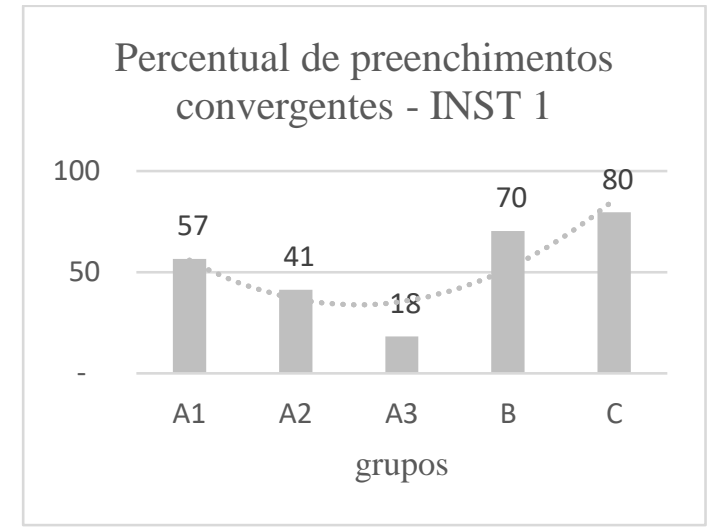

FIGURA 1- resultados do instrumento
Percentual de preenchimentos convergentes - INST 2

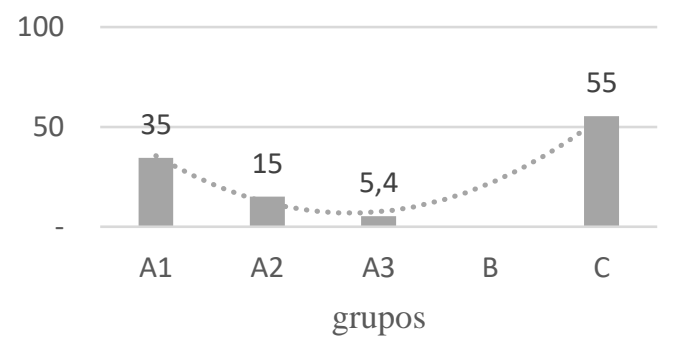




\section{REVISTA DA ABRALIN}

Como esperado, os Gráficos representados nas figuras 1 e 2 mostram que o grupo C (sem privação de língua durante a infância e perda auditiva entre 5 e 7anos) apresenta melhores resultados que os grupos A1, A2 e A3 nos dois instrumentos aplicados. Embora os participantes do grupo B (surdos de segunda geração) não tenham se submetido à leitura do segundo texto, também demonstraram resultados melhores que os informantes dos grupos A, ao menos no INST 1.

Ainda que os percentuais dos grupos B e C apresentem alguma instabilidade no reconhecimento de restrições semânticas e morfossintáticas para a recuperação de alguns itens parcialmente lacunados, os resultados apontam para melhor desenvolvimento da habilidade leitora desses indivíduos surdos que tiveram acesso à L1 (LIBRAS ou PB) desde o nascimento. Em outros casos, o desenvolvimento tardio da L1, que afeta a emergência de conhecimento de mundo, parece confirmar os consequentes baixos resultados em atividade de compreensão leitora, sobretudo entre os informantes do grupo A3.

Desconsiderando o grupo B, observa-se uma queda no percentual de preenchimentos convergentes do INST 1 para o INST 2 nos quatro grupos. Essa informação justifica nossa intenção de verificar se o assunto não familiar aos sujeitos, ainda que o texto do INST 2 não aborde questões técnicas de áreas específicas do conhecimento, influenciaria no alcance da compreensão, afetando a capacidade de recuperação dos itens parcialmente lacunados.

Os gêneros escolhidos - notícia e folheto - têm um nível alto de circulação na sociedade em geral, entretanto, o texto do folheto (INST 2) apresenta algumas características de mais a menos favoráveis à compreensão e que devem ser apontadas. O tipo de folheto em questão, apesar de gratuito, tem acesso limitado, já que sua disponibilização está restrita a alguns estabelecimentos comerciais e culturais. Sendo um texto de divulgação, com o objetivo de apresentar um roteiro de livrarias e convidar o público-alvo leitor, encontram-se construções bastante frequentes em gêneros do cotidiano, como as copulativas e as imperativas. Em contrapartida, o texto traz informações históricas que demandam acionamento de conhecimento prévio mais amplo que o primeiro texto.

O texto do INST 1, em sua composição verbal e não verbal, aborda tema relacionado a esportes olímpicos praticados por surdos. Além de a notícia ter sido veiculada nas mídias e redes sociais, vários participantes relataram conhecer atletas surdos que participaram das surdolimpíadas de 2017, sediadas no Brasil. Nosso pressuposto, então, era de que este texto trazia conteúdo informativo previamente conhecido.

O fator familiaridade com o tema é um aspecto importante na recuperação do significado de palavras e de construções maiores da L2, que possivelmente os participantes da pesquisa não conhecessem. Tal familiaridade, quando se comparam os resultados dos dois textos, parece ter sido fator relevante, no entanto, insuficiente para alcance de boa compreensão leitora, dados os baixos resultados da maioria dos participantes dos grupos A, cujos preenchimentos divergentes passaremos a observar.

Considerando que esses participantes tinham algum conhecimento prévio da temática abordada no texto 1, nossa hipótese é a de que o fator impeditivo de uma boa compreensão leitora está atrelado 


\section{REVISTA DA ABRALIN}

ao baixo conhecimento linguístico. Os preenchimentos divergentes observados nos dois trechos a seguir demonstram que a compreensão dos participantes foi parcial ou totalmente impedida, tendo em vista o produto gerado com os preenchimentos para composição das construções lacunadas.

(1) O Brasil fez história na $23^{\mathrm{a}}$ Surdolimpíada, realizada na Turquia. No evento, que começou no último dia 18 e segue até o dia 30 deste mês, o brasil o Guilherme Maia conquistou a primeira medalha de ouro brasiliniciar na história da competição. Com o tempo de 1min52s55, o nada antes marcou o novo recorde mundição dos 200m livre. A delegação brasil principais selecionada para o campe dentro tem 99 atletos. (part.20_A3)

(2) O Brasil fez história na $23^{a}$ Surdolimpíada, realizada na Turquia. No evento, que começou no último dia 18 e segue até o dia 30 deste mês, o brasil por Guilherme Maia conquistou a primeira medalha de ouro brasil ao na história da competição. Com o tempo de 1min52s55, o nadar marcou o novo recorde mundial dos $200 \mathrm{~m}$ livre. A delegação brasil ao selecionada para o campe $\underline{\tilde{a} \mathbf{0}}$ tem 99 atleto. (part.19_A3)

Nos exemplos (1) e (2), representativos do grupo A3, ainda que algumas lacunas tenham sido preenchidas com palavras e morfemas do $\mathrm{PB}$, tais preenchimentos não possibilitam relação semântica entre os itens adjacentes nem relação sintática possível entre as construções. A maioria das ocorrências indica que as lacunas foram preenchidas sem pareamento possível de forma e significado dentro do contexto, isto é, os participantes demonstram insuficiente conhecimento colocacional da construção nominal, para que as palavras signifiquem combinadas a outras. Os preenchimentos com palavras onde se esperava inserção de morfemas, ou de parte deles, indicam que apenas os radicais parecem oferecer informação suficiente para a atividade leitora, o que apontaria para a ainda não constituição de uma base morfossintática convergente à do $\mathrm{PB}$, impedindo acesso pleno às informações do texto.

Os preenchimentos sugerem que a representação do que seja leitura para o grupo A3 está relacionada à identificação de palavras isoladas, tomadas sem relação com a posição e a forma que elas assumem em relação a outras. Essa parece ser a representação de leitura que a escola tem ajudado a construir, ao menos para parte da população surda. A baixa consciência linguística observada nos preenchimentos dos instrumentos não permite indicar que os participantes do grupo A3 sejam leitores e usuários autônomos do PB.

Os exemplos (3) e (4) a seguir, representativos do grupo A2, foram gerados por participantes cuja aprendizagem da LIBRAS e do PB se iniciou ainda na infância, em idade escolar.

(3) O Brasil fez história na $23^{a}$ Surdolimpíada, realizada na Turquia. No evento, que começou no último dia 18 e segue até o dia 30 deste mês, o brasileiro Guilherme Maia conquistou a primeira medalha de ouro brasileiro na história da competição. Com o tempo de 1min52s55, o nadar 


\section{REVISTA DA ABRALIN}

marcou o novo recorde mundi dos 200m livre. A delegação brasileiro selecionada para o campe $\underline{\tilde{a} \mathbf{o}}$ tem 99 atlet $\underline{\text { a. }}$ (part.12 _A2)

(4) O Brasil fez história na $23^{a}$ Surdolimpíada, realizada na Turquia. No evento, que começou no último dia 18 e segue até o dia 30 deste mês, o brasil surdo eiro Guilherme Maia conquistou a primeira medalha de ouro brasileiro na história da competição. Com o tempo de 1min52s55, o nadação marcou o novo recorde mundial dos 200m livre. A delegação brasileiro selecionada para o campeoneto tem 99 atlet $\underline{\text { a. }}$ (part.18_A2)

Os preenchimentos indicam que os participantes demonstram reconhecer a forma e o significado de alguns itens lacunados, apesar de não terem automatizado os padrões combinatórios de concordância de gênero e número ([A delegação brasileiro]; [99 atleta ]), veiculados em exemplares escritos em variante culta do PB. Ainda se verifica baixo desenvolvimento de consciência metacognitiva dos participantes desse grupo. Embora sejam raras as ocorrências que indiquem regressão para reparo (rasuras) no grupo A2, dentre as quais estão o primeiro preenchimento gerado pelo participante 18, no exemplo (4), essa estratégia pode ser indicativa de algum desenvolvimento de consciência metacognitiva, ainda que pouco consistente, de que a atividade leitora prevê retornos a trechos já lidos, assim como acontece com atividades de fala e de produção escrita.

O terceiro, o quarto e o quinto itens lacunados ('nadar/ção'; 'mundi_-/al' e 'campeão/oneto') ainda apontam para uma instável atividade leitora do grupo. As escolhas dos morfemas verbal [r] e nominal [ção] no preenchimento do item 'nadador' parecem indicar não haver identificação da informação de que o brasileiro Guilherme Maia é um nadador. O significado do item 'mundial' isoladamente ou pelas pistas dos itens adjacentes não foi acessado pelo participante 12, o que sugere a incompreensão do enunciado, apesar de a construção [marcar recorde + mundial] constituir uma combinação de uso frequente em textos da área do esporte.

É possível que a polifuncionalidade observada em alguns itens (adjetivos, substantivos e verbos) na LIBRAS, língua utilizada com maior frequência que o PB, seja um traço transferido e supergeneralizado que explique a emergência de uma morfologia fraca, sugerindo competição no uso do PB. Os morfemas, ou parte deles, parecem estar em constante competição observável em vários preenchimentos de diferentes informantes dos grupos A. Os preenchimentos sugerem fraca consciência morfológica em PB: 'campeonato' ou 'campeão', 'mundial' ou 'mundição', 'brasil' ou 'brasileiro', 'nadar', natação ou 'nadador'. Mesmo o grupo A1, com melhor percentual de preenchimentos que A2 e A3, demonstrou divergências semelhantes entre os sujeitos participantes, como mostram os exemplos (5) e (6).

(5) O Brasil fez história na 23a Surdolimpíada, realizada na Turquia. No evento, que começou no último dia 18 e segue até o dia 30 deste mês, o brasil do Guilherme Maia conquistou a primeira medalha de ouro brasilde na história da competição. Com o tempo de 1min52s55, o nadador 


\section{REVISTA DA ABRALIN}

marcou o novo recorde mundial dos $200 \mathrm{~m}$ livre. A delegação brasileiro selecionada para o campe $\underline{\tilde{a} o}$ tem 99 atletas. (part.7_A1)

(6) O Brasil fez história na $23^{\mathrm{a}}$ Surdolimpíada, realizada na Turquia. No evento, que começou no último dia 18 e segue até o dia 30 deste mês, o brasil2017 Guilherme Maia conquistou a primeira medalha de ouro brasil2017 na história da competição. Com o tempo de 1min52s55, o nadando marcou o novo recorde mundial dos 200m livre. A delegação brasil_2017 selecionada para o campe ão tem 99 atleta . (part.8_A1)

O exemplo 5 indica que o participante 7 não reconheceu a informação relativa à nacionalidade determinada pela função adjetiva dos dois primeiros itens do trecho, mas a reconheceu na terceira ocorrência de 'brasil__' ([A delegação brasileiro] $)$, embora não demonstre acionar estratégias metacognitivas (e.g. meta-atenção) relativas tanto ao padrão de combinação, referente à concordância de gênero entre especificador do núcleo nominal e seu complementador, quanto ao retorno às construções anteriores para reavaliar os preenchimentos 'do' e 'de'.

O participante 8 demonstra, nos preenchimentos com '2017' nas três lacunas, busca por regularização, característica de aprendizes de L2, como mostram estudos de Hilpert (2019) e Goldberg (2019) com aprendizes de inglês. O contato com o input escrito da construção [Brasil 2017], com alta frequência de ocorrência na época dos eventos olímpicos, parece ter sofrido efeito de entrincheiramento dos dois itens, gerando armazenamento desse chunk. Nossa hipótese é que, sendo um competidor mais robusto que o item 'brasileiro', [Brasil 2017] foi acionado durante a atividade leitora.

Os dois participantes, assim como outros 18, apresentaram preenchimento divergente para o item 'campeonato' cuja forma escolhida, apesar de morfossintaticamente compatível com o padrão da construção em que se insere ([para o campeão] ]), fere restrição semântica determinada pelo contexto. Essa ocorrência via atividade leitora e aquelas via atividade de produção analisadas no início deste artigo, demonstram uma forte evidência para a hipótese de que a atenção ao significado veiculado pelo radical é priorizada, enquanto que o morfema revelador de categoria gramatical e, portanto, de sua função na construção, não parece atuar na organização dos sentidos emergentes do texto.

A tendência a privilegiar o sentido às pistas gramaticais, é observada em aprendizes ouvintes de L2, como demonstraram Gass e Selinker (1994), não exclusivas de aprendizes surdos, portanto. Ocorre que, se os dois tipos de pistas, semântico-pragmáticas e morfossintáticas, não atuam juntas, em razão de uma delas se apresentar fraca ou opaca aos aprendizes, o papel da instrução explicita, prevista em uma didática aquisicional, é ensinar-lhes a acionarem conscientemente estratégias metacognitivas que façam emergir os sentidos do texto (dependentes de padrões combinatórios), especialmente quando o assunto abordado não lhe é familiar.

Dos nove participantes do grupo A1 (precoce acompanhamento fonoaudiológico e LIBRAS tardia), apenas três demonstraram bom desempenho na atividade leitora, o que elevou o percentual total de acertos (57\%) em quase 50\%. Essa diferença entre os participantes indica que, além das condições aquisicionais de uma L1, outros aspectos, - afetivos, sociais, econômicos e educacionais 


\section{REVISTA DA ABRALIN}

-, em termos qualitativos e quantitativos, estão envolvidos no processo, gradual e com necessária frequência, de desenvolvimento de língua.

Os seis participantes com desempenho mais baixo do grupo A1 demonstram algum conhecimento prévio sobre o assunto abordado - as Surdolimpíadas de 2017 -, no entanto, ainda revelam baixo domínio morfossintático do PB, o que impede boa compreensão do texto. Estes participantes tiveram acompanhamento fonoaudiológico precoce por um tempo médio de 10 anos, o que, no experimento aplicado, não revelou diferença no sistema emergente da L2, em relação aos participantes do grupo A2, que tiveram acompanhamento iniciado mais tarde, em fase de inserção escolar, por um tempo médio de 9 anos.

Os resultados da atividade leitora do INST 1, discutidos até aqui, evidenciam que o conhecimento prévio não parece ser fator de maior destaque para leitura em L2. A seguir, continuamos a investigação dos preenchimentos que emergiram durante a leitura do INST 2.

A composição verbal e não verbal do INST 2 integra um conjunto de informações socioculturais que marcaram a história do Centro da cidade do Rio de Janeiro, por onde atualmente passa um roteiro com 53 livrarias. Tais informações se concentram na segunda metade do texto, o que gera uma expectativa de na maior dificuldade de preenchimento dos itens aí lacunados. No entanto, palavras como 'livrarias' (95\%), 'especialidades' (95\%) e 'leitores' (73\%), localizadas no primeiro parágrafo, também apresentaram preenchimentos com altos índices de divergências relativas à recuperação não só da forma, mas também do significado. Os exemplos a seguir evidenciam tais preenchimentos.

(7) Temos o prazer de apresentar a $4^{\mathrm{a}}$ edição do Roteiro das Livrarias do Centro Histórico do Rio de Janeiro. São 53 livros com as respectivas especiais, para facilitar a busca dos leites. (part..2_A1)

(8) Temos o prazer de apresentar a $4^{a}$ edição do Roteiro das Livrarias do Centro Histórico do Rio de Janeiro. São 53 livro com as respectivas especial, para facilitar a busca dos leituro. (part.17_A2)

(9) Temos o prazer de apresentar a $4^{a}$ edição do Roteiro das Livrarias do Centro Histórico do Rio de Janeiro. São 53 livr $\underline{\text { irios }}$ com as respectivas especiais, para facilitar a busca dos leitalismo. (part.20_A3)

(10) Temos o prazer de apresentar a $4^{a}$ edição do Roteiro das Livrarias do Centro Histórico do Rio de Janeiro. São 53 livros com as respectivas especialista, para facilitar a busca dos leitores. (part.21_C)

Os exemplos dos grupos A e C revelam, logo no primeiro preenchimento do texto, que os participantes não acionam estratégias metacognitivas que envolveriam retornos aos trechos já preenchidos, a fim de repararem compreensão equivocada de que o texto trataria de um roteiro com 53 livros. 


\section{REVISTA DA ABRALIN}

Além disso, a informação verbal do título que compõe a figura ("ROTEIRO DAS LIVRARIAS") e aquela trazida na primeira linha do texto parece não terem sido associadas, ou nem mesmo acessadas, às informações seguintes apresentadas no texto. É possível que haja aí mais uma evidência para nossa hipótese de que a morfologia é pista fraca para a maioria dos participantes da pesquisa e provavelmente para a maior parte da população surda.

O primeiro preenchimento do exemplo (9) - [São 53 livririos] -, apesar de indicar que não houve recuperação integral da forma grafofonêmica do item, aponta para compreensão de que o roteiro não é de livros, mas de lojas que vendem livros. No entanto, outros três preenchimentos do participante, no parágrafo seguinte, demonstram inconsistência na compreensão do texto, já que seleciona preenchimentos tais como [muitas livros]; [livros religios $\underline{a s}$ ] e [nossas livros]. Esse tipo de preenchimento, assim como em [com as respectivas especial] e [a busca dos leites], evidencia competições em que o vencedor é o item mais saliente na rede construcional do aprendiz, independentemente de sua composição semântica, morfológica e sintática.

Várias ocorrências ainda sugerem relação com possível efeito da prática inconsistente de leitura labial, a promover baixa percepção dos constituintes de fronteiras das palavras, como temos discutido em Soares (2018 e 2020). Tal experiência linguística, geralmente de baixa qualidade perceptual, oferece input de formas incompletas percebidas pelo canal visual das pessoas surdas, que resultam em um repertório construcional com muitos apagamentos e com fracas conexões entre exemplares.

Como o acionamento de conhecimento prévio integram atividades de leitura, os resultados percentuais decrescentes entre os dois experimentos corroboram achados de várias pesquisas sobre a necessidade de ampliar o letramento do público-alvo surdo, seja em PB ou em LIBRAS. Não atribuímos, porém, a queda de rendimento das amostras do INST 2 exclusivamente à pouca familiaridade dos aprendizes com o assunto abordado, já que o INST 1, que supomos trazer assunto familiar, não teve nível de preenchimento convergente tão alto para todos os grupos, que justificasse tal pressuposição. Outro aspecto importante é que os tipos de divergências encontradas no INST 2 são de mesma natureza daqueles encontrados nos INST 1, isto é, de forma que afetam significado.

A questão parece estar relacionada primeiro à proficiência linguística dos informantes, que não os deixa acessar as informações veiculadas nos textos, e depois à familiaridade com os assuntos abordados. Não basta que haja conhecimento prévio para fazer emergir compreensão de um texto, se o aprendiz não tiver constituído uma representação construcional suficiente da língua em que o assunto é veiculado. Estar bem informado sobre a temática dos esportes olímpicos, por exemplo, não torna um indivíduo capaz de ler sobre esse assunto, por exemplo, em italiano ou alemão, se ele não alcançou proficiência suficiente para construção de sentidos com o código dessas línguas. Ou seja, os dois fatores, conhecimento prévio, representado na mente via LIBRAS ou via qualquer outro sistema, e conhecimento do código da L2 e de seu funcionamento, atuam de maneira integrada para a compreensão das informações trazidas nos textos.

Com esse tipo de análise, dois fatores se mostram proeminentes. O primeiro diz respeito àqueles participantes que tiveram contato com uma língua (LIBRAS ou PB) precocemente e, portanto, desenvolveram habilidades linguísticas de compreensão nas modalidades ou sinalizada ou oral, antes 


\section{REVISTA DA ABRALIN}

de aprenderem a usar a modalidade escrita (ler e escrever). Estes sujeitos demonstram ter desenvolvido uma rede construcional na L1 que permite reconhecimento de padrões construcionais dinâmicos e complexos bem diferentes daqueles que constituem o sistema caseiro de comunicação usado inicialmente por parte dos participantes.

O segundo fator se refere a propostas (i) de atividade de compreensão leitora em PB escrito antes mesmo de o aprendiz surdo ter atingido nível de proficiência nesta língua, compatível com tal atividade e (ii) de atividades inadequadamente denominadas como de compreensão leitora, em que se entrega ao aprendiz uma tradução/interpretação de um texto que teria tantos aspectos a serem ensinados, inclusive contrastivos entre LIBRAS e PB, mas que ficam para... quem sabe um dia.

Esses dois fatores fundamentais têm implicações sérias na natureza do produto que emerge na mente do aprendiz surdo e no subsequente acionamento em atividades de leitura na L2. A questão que se coloca, portanto, é o quanto de conhecimento da L2 se faz necessário para atividade leitora, ainda que haja conhecimento prévio do assunto, a exemplo do texto do INST 1. O contexto não se mostrou suficiente para recuperação do item (forma e significado) nos casos em que se observam ausência de preenchimentos, preenchimentos que não formam palavras em $\mathrm{PB}$, preenchimentos com um item lexical e preenchimentos que geram item de outro campo semântico. O inconsistente conhecimento linguístico parece ser fator limitador no uso da língua escrita para os participantes surdos universitários.

A partir das observações sobre o produto das atividades leitoras dos participantes da pesquisa, cujas explicações tiram a sobrecarga do conhecimento sobre a temática dos textos, apresento na próxima seção uma tipologia de divergências explicadas principalmente por processos de analogização que atuam na emergência de línguas, esperando tornar mais robustos os resultados sugeridos durante as análises desta seção.

\section{Resultados}

De acordo com os comprometimentos observados durante as análises, foram definidos oito esquemas de formas competidoras (preenchidas) e não reconhecidas (sem preenchimento). Estes esquemas compõem uma tipologia de divergências encontradas nos 46 instrumentos, cujo objetivo é tornar visível parte da representação do PB no sistema de competidores usado pelos 24 participantes da pesquisa. Os esquemas não combinam propriedades léxico-gramaticais convergentes, tanto para compor o padrão construcional [(ESP) N (COMP)] quanto para compor o texto como um todo. 


\section{REVISTA DA ABRALIN}

\begin{tabular}{|c|c|}
\hline \multicolumn{2}{|c|}{ ESQUEMAS DE FORMAS COMPETIDORAS DIVERGENTES OU NÃO RECONHECIDAS } \\
\hline $\begin{array}{l}1-[\text { radical + morfema congruente com signifi- } \\
\text { cado e categoria da palavra-alvo }]=[\text { cognato }]\end{array}$ & $\begin{array}{l}\text { [para o campeão] } \\
\text { [livros gerais] }\end{array}$ \\
\hline $\begin{array}{l}2-[\text { radical }+ \text { morfema de outra categoria }]= \\
{[\text { cognato }]}\end{array}$ & $\begin{array}{l}\text { [a primeira participar do Brasil] } \\
\text { [com as respectivas especialmente] }\end{array}$ \\
\hline $\begin{array}{l}\text { 3- [radical + morfema divergente aos padrões } \\
\text { de concordância }]\end{array}$ & $\begin{array}{l}\text { [o Brasil soma quatro medalha] } \\
\text { [da poetisa francês Jane Catulle Mendes] }\end{array}$ \\
\hline $\begin{array}{l}\text { 4- [radical + morfema desassociado da pala- } \\
\text { vra-alvo] }\end{array}$ & $\begin{array}{l}\text { [o carater Heron Silva] } \\
\text { [cronograma perspicaz da alma humana] }\end{array}$ \\
\hline $\begin{array}{l}\text { 5- [radical + morfema com alteração ortográ- } \\
\text { fica] }\end{array}$ & $\begin{array}{l}\text { [a delegação brasilirera }] \\
\text { [o novo recorde mundinal] } \\
\text { [para o campeanto }]\end{array}$ \\
\hline 6- [radical + sequência não produtiva] & $\begin{array}{l}\text { [o novo recorde mundição] } \\
\text { [a busca dos leitivos] } \\
\text { [o judodor Alexandre Fernandes] }\end{array}$ \\
\hline 7- [radical + item pleno] & $\begin{array}{l}\text { [um marco na história brasil 2017] } \\
\text { [a primeira participa surda] }\end{array}$ \\
\hline $8-[$ radical $+\varnothing]$ & $\begin{array}{l}\text { [uma par_-_ no dia-a-dia apressado] } \\
\text { [carioca quer__-_] }\end{array}$ \\
\hline
\end{tabular}

QUADRO 3 - Tipologia de formas competidoras Fonte: Soares (2018)

Os achados das análises indicam relativa sistematicidade com que os preenchimentos divergentes ocorreram, o que possibilitou essa proposta de tipologia de divergências comuns empregadas na formação das palavras nominais lacunadas. Partindo do padrão geral de colocações do PB [(ESP) N (COMP)], constituído por, ao menos, um desses três "atratores gramaticais", para que palavras componham significado ao assumirem dada posição nas construções nominais selecionadas, é preciso que o aprendiz as reconheça. Apesar de, aos olhos dos aprendizes de L2, padrões morfossintáticos não se mostrem claramente distinguíveis, e por isso tendem a ser supergeneralizados, há detalhes que os diferenciam. Sendo assim, os "atratores gramaticais", com seus modos de comportamento preferidos que constituem padrões abstratos do sistema complexo da L2, devem ser aprendidos, sobretudo pelo contato robusto com input da L2, via atividades de leitura.

O esquema 1 [cognatos] agrupa um tipo de formas competidoras emergentes durante a atividade leitora (e.g. [para o campeão]). Observado em todos os grupos, esse tipo de divergência parece indicar que os itens acessados são decorrentes de uma estratégia de leitura superficial, e não analítica, em que o foco é a identificação de palavras e não suas relações intra e interconstrucionais. Embora os preenchimentos correspondam a cognatos dos itens-alvo e, portanto, partilhem o mesmo radical, 


\section{REVISTA DA ABRALIN}

os itens resultantes ferem restrições morfossintáticas e semânticas, que não apontam para a constituição de memória enriquecida com amplo repertório do PB.

A análise do tipo de divergência agrupada no esquema 1 aponta para a primeira evidência de que muitos surdos, a exemplo dos participantes desta pesquisa, não alcançam bons níveis de proficiência em PB em razão de o léxico emergente não ser constituído de traços que envolvem forma, significado e função da palavra usada em construções do PB.

Assim como o esquema 1, o esquema 2 resulta em itens cognatos que partilham o radical, mas não partilham categoria gramatical e função da palavra-alvo (e.g. [a primeira participar do Brasil]; [o nadar campeão olímpico]). Os itens vencedores da competição configuram relações interlexicais que não constituem um padrão combinatório possível em PB, gerando agramaticalidade. Esses dois primeiros tipos de divergências analisadas indicam evidências importantes para caracterização da representação cognitiva do PB usado por aprendizes surdos.

A troca do morfema final, observada nos preenchimentos, parece ser uma evidência de que a organização do conhecimento linguístico da L2 não contempla informação sobre a categoria das palavras. As conexões lexicais formadas pelo partilhamento da forma e do significado das palavras

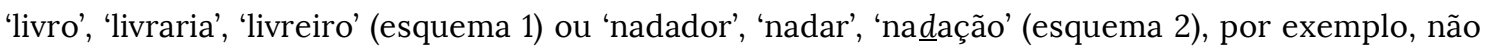
demonstram estarem completas, por isso competem entre si. Ainda que o radical seja partilhado, os morfemas derivacionais das palavras do PB não parecem relevantes para a constituição do significado funcional que origina palavras com significado diferenciado, além de definirem sua colocação em construções. Os participantes ainda não demonstram pleno reconhecimento das relações de identidade entre categorias abstratas integrantes do léxico do PB, que possibilitam a emergência de itens encaixados em padrões construcionais.

Os preenchimentos divergentes constituem pistas indicativas de que as representações morfológicas das palavras e suas associações sintagmáticas e paradigmáticas são ainda fracas, provavelmente, devido à baixa frequência de uso e, portanto, não constituem chunks fortes para armazenamento rico na memória. Ainda que todos os exemplares com as sequências [livr-] e [nada-], por exemplo, já tenham sido percebidos e usados em algum momento pelos participantes, se não houver frequência de uso em construções que combinam elementos atratores [(ESP) N (COMP)], formarão representações fracas na memória. Tais representações não contemplam a noção de que as palavras e as construções em que elas se inserem possuem posições esquemáticas a serem preenchidas por um conjunto de itens (morfemas e palavras) não aleatórios. Por isso, experiências com palavras isoladas ou com textos em versão traduzida não oferecem condições de percepção e armazenamento da riqueza de características linguísticas e discursivas das construções que compõem o sistema da L2.

O esquema 3 envolve os preenchimentos que apresentam marcas morfológicas de gênero e/ou de número, divergentes das exigidas ou pelos itens adjacentes ou pelo contexto (e.g. [oito seção de treino]; [muitas livro]; [Barão do Rio Branco, carioca querida] ). Mais que o acréscimo dos morfemas -a e/ou -s por um processo de analogia às marcas do item adjacente, o padrão de concordância entre os itens do PB escrito pode exigir outra combinação morfológica. No primeiro exemplo, é provável que o morfema [-ções] não tenha sido recuperado por constituir poucos e fracos exemplares 


\section{REVISTA DA ABRALIN}

na memória dos participantes, visto que apenas quatro apresentaram preenchimento convergente para tal construção. Tal fraqueza pode ser efeito de baixa frequência de uso da sequência [-ções] em itens do $\mathrm{PB}$, o que não contribui para seu armazenamento como um chunk que poderia tornar robustas outras conexões de [ESP(plural) $\left.\operatorname{RADICAL}_{((\varsigma o ̃ e s)}\right]$.

No terceiro exemplo, a relação contextual solicita do aprendiz compreensão leitora para identificar que o referente do item 'carioca' (cuja forma não se altera em relação ao gênero do item com o qual se combina) é um nominal - barão - que designa título a um homem e que, portanto, o nominal 'querid-', que complementa 'carioca', deve ser materializado com morfema -o e não, -a, como induz o último grafema do núcleo da construção. Esses detalhes compõem idealmente uma memória rica por experiências com construções frequentes na língua, tais como [o campeonato carioca], [o carioca bronzeado], [a festa carioca], em que o item 'carioca' não tem sua forma modificada, nem implica mudança morfológica em seu adjacente.

A convenção relativa à marca de gênero das palavras é de fato um aspecto do PB que causa dúvidas a aprendizes surdos ou estrangeiros, que tendem ou a transferir o padrão da L1 ou supergeneralizar um padrão a partir de outro mais frequente. Esse tipo de pista não é transparente ao aprendiz de L2, sobretudo se não há padrão semelhante na L1, portanto, depende de instrução explícita por meio de atividades formais de ensino. A disciplina de português L2, bem orientada por uma didática aquisicional, tem o papel de oferecer input por meio de atividades que proporcionem percepção do funcionamento desses padrões construcionais.

Os três primeiros esquemas correspondem à maioria das divergências encontradas. Isso sugere uma caracterização, em termos de percepção e de processamento da informação linguística da L2. Esses esquemas compõem a representação do sistema de competidores que parece estar representado e em uso pelos participantes surdos. Considerando as exigências inerentes à modalidade escrita, estratégias de aprendizagem (consciência metacognitiva), que a partir do uso salientam aspectos variados sobre o funcionamento da L2, devem ser exploradas durante a escolarização, com vistas a tornar aprendizes autônomos para atividades de produção e de compreensão escritas.

As formas competidoras que constituem o esquema 4 [radical + morfema desassociado da palavra-alvo] não foram observadas em todos os grupos. As ocorrências arroladas neste esquema evidenciam que a compreensão leitora não foi suficiente para permitir acesso à palavra-alvo, o que leva o participante a focar na forma e não, no significado (e.g. [o carater Heron Silva].

Os preenchimentos divergentes com a sequência 'er', somados aos preenchimentos dos três esquemas anteriores, contribuem para indicação de baixo nível de desenvolvimento de consciência morfológica que não ativa o fator analisabilidade das palavras derivadas. Os participantes poderiam, pelo processo de analogia com outros sufixos formadores de agentes e que formam chunks produtivos, propor preenchimento com os morfemas [-ista], [-eiro] ou [-or], por exemplo. Mesmo não resultando em uma palavra real, tal estratégia indicaria consciência metacognitiva, importante para aprendizagem de L2.

Os preenchimentos categorizados no esquema 5 [radical + morfema com alteração ortográfica] indicam que a sequência de grafemas que forma os itens lacunados possivelmente ainda 


\section{REVISTA DA ABRALIN}

não tem representação tão forte na memória dos informantes que produziram esse tipo de divergência, visto que estes não acessam a forma regular da palavra-alvo (e.g. [o novo recorde mundinal]; [para o capento]. Esse tipo de divergência também acomete aprendizes ouvintes, como mostra estudo de Lauffer (1997).

Dez participantes apresentaram preenchimento com alteração ortográfica, mas apenas quatro (A2) foram reincidentes em divergências relativas à inserção, omissão e troca na ordem dos grafemas. As poucas ocorrências desse tipo indicam que os participantes universitários não foram fortemente afetados por esse tipo de divergência, ao menos quando parte da sequência, que constitui a palavra, é dada.

Durante a aplicação dos instrumentos, observamos que alguns participantes usaram a estratégia de soletração manual (datilologia) com a finalidade de recuperarem a sequência grafêmica do item lacunado. Essa estratégia parece estar ligada à associação transmodal (letra escrita e letra manual) para recuperação de itens que ainda não se constituem fortes na memória. A recuperação da sequência completa dos grafemas se torna menos custosa caso os grafemas sejam agrupados em chunks menores que as palavras. Isto é, com base em estudos sobre memória (MILLER, 1956; NEWELL, 1990) parece tarefa menos custosa lembrar de uma sequência com dois blocos do que lembrar de vários segmentos em sequência. Essas observações sugerem a necessidade de desenvolvimento de algum nível de consciência morfológica para aprendizagem de L2 escrita.

O esquema 6 [radical + sequência não produtiva] também traz divergências intralexicais que afetam relações interlexicais relativas à não emergência de sentidos, observadas em todos os grupos. As formas competidoras acessadas durante a atividade leitora e reproduzidas nas lacunas constituem não-palavras, embora a maioria dos preenchimentos apresentem sequências grafotáticas possíveis em PB (e.g. [a busca dos leitivo]; [no lançaões do livro]).

Esse tipo de ocorrência também representa um quantitativo baixo de divergências. A maioria foi encontrada nos instrumentos dos participantes do grupo A3. Alguns preenchimentos desses participantes merecem destaque: [o judodor Alexandre Fernandes] e [marcos do passado colonial, imperial e modernal].

Como evidência para ativação da consciência metacognitiva (atenção e consciência metalinguística) durante a atividade leitora, os dois participantes demonstram reconhecer padrões possíveis de formação de palavras: [RADICAL+ dor] que indica papel de agentes e [RADICAL + al] que indica ideia de relação. Os dois preenchimentos parecem ser decorrentes de analogização, sendo o preenchimento do item 'modernal' possivelmente motivado pelos dois itens à esquerda.

O resultado do processamento analógico pode agir tanto positiva quanto negativamente (supergeneralização) na compreensão e na produção da mensagem, o que é comum durante aprendizagem de L2, por surdos ou ouvintes, principalmente com itens de uso pouco frequente.

As divergências que constituem o esquema 7 [radical + item pleno] são referentes ao não reconhecimento de que a sequência lacunada não apresenta forma e significado suficientes em PB para compor a construção em que se insere, o que motivou a colocação de um item pleno. Apenas os dois 


\section{REVISTA DA ABRALIN}

participantes do grupo C (surdez entre 5 e 7 anos) não produziram esse tipo de divergência que, mais uma vez, acometeu em maior quantidade os preenchimentos do grupo A3.

A inserção de um novo item pode apresentar combinação localmente possível com um dos itens adjacentes, mas não compõe significado compatível com todos os itens da construção (e.g. [valem uma para que no dia-a-dia apressado]). Apesar de os itens funcionais 'para' e 'que' formarem uma combinação frequente na língua, que serve à expressão de finalidade, não faz emergir significado na construção em que se inserem. Essa é mais uma ocorrência em que observamos falha na identificação da categoria gramatical de nominais, que se coloca após um especificador e assume função, neste caso, de complementar um verbo (valer).

Alguns preenchimentos do esquema 7 (e.g. [o brasil nadador Guilherme Maia]; [a primeira medalha brasil vez na história da competição]) sugerem que os participantes percebem o item lacunado como a forma completa com função de especificador ou complementador que pode assumir colocação à esquerda ou à direita do núcleo. De acordo com os exemplos disponíveis nos dicionários consultados $^{3}$, os itens 'Brasil' e 'brasileiro' assumem mesma forma sinalizada em LIBRAS, transferindo o traço de polifuncionalidade desses itens, como discutido na seção anterior.

Alguns itens, por assumirem forma única em LIBRAS, apesar de sua correspondência com funções gramaticais diferentes, quando transferidos para construções em PB, constituem agramaticalidade. Esse caso de transferência negativa do padrão de uso da LIBRAS para o PB, compete com padrões desta língua. Ainda que a LIBRAS seja uma língua espaço-visual e sem escrita alfabética, a competição relativa à forma do item ocorre via transferência ou associações de padrões abstratos dessa língua, como a não marcação morfofonológica observada em outros esquemas.

O esquema 8 [radical $+\varnothing]$ é o último caso analisado em nossa tipologia. Esse esquema é decorrente do não preenchimento de 100 lacunas (de um total de 1144), em maior parte daquelas do INST 2 , em que verificamos o efeito do fator de menor familiaridade com a temática abordada. O maior percentual de lacunas em branco foi mapeado nos instrumentos do grupo A3.

O não preenchimento de lacunas (e.g. [a primeira participa___ do Brasil]; [a dedica e o esforço citados]) é mais um elemento que se soma à avaliação de que a maioria dos participantes têm baixo repertório para uso - leitura e escrita - do PB. Nem a alta produtividade do sufixo [-ção], cujo grande número de exemplares constitui a categoria do substantivo em PB, ofereceu aos participantes maior probabilidade de acionar conexões com diferentes morfemas radicais. O esquema 8 traz mais um indicativo da fraqueza morfológica na constituição do conhecimento linguístico representado cognitivamente para a maioria dos participantes. A figura a seguir é uma tentativa de representar o repertório da maioria dos participantes da pesquisa.

\footnotetext{
${ }^{3}$ Dicionário da Língua Brasileira de Sinais (http://www.acessibilidadebrasil.org.br/libras) e Novo Deit-Libras: Dicionário Enciclopédico Ilustrado Trilíngue da Língua de Sinais Brasileira (Libras) baseado em Linguística e Neurociências Cognitivas (CAPOVILLA; RAPHAEL; MAURICIO, 2009)
} 


\section{REVISTA DA ABRALIN}

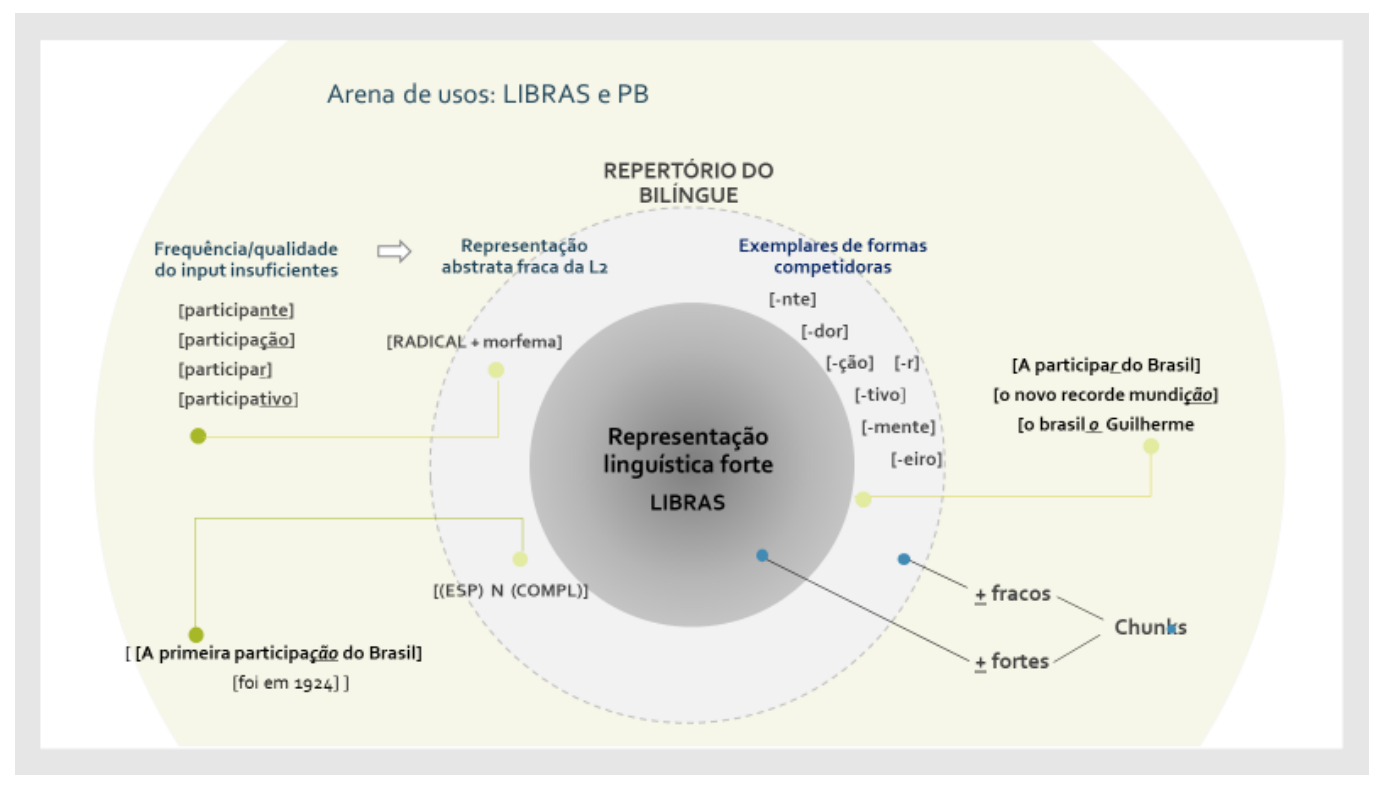

FIGURA 3 - Representação do repertório linguístico

Fonte: a autora

Os resultados indicam que a constituição do conhecimento linguístico da L2, de mais da metade dos surdos universitários participantes desta pesquisa, ainda não parece robusta para uso autônomo da língua, sem dependência de tradução, mesmo após longos anos de escolarização. O ponto fundamental aqui é que, antes de poderem ou não ser considerados usuários do PB, sobretudo leitores, é preciso considerar as razões pelas quais esses sujeitos não constituíram um sistema com exemplares fortes em que suas relações resultem em construções que pareiam forma, significado e uso.

Se as impropriedades verificadas na escrita durante a educação básica continuam no ensino superior, entendemos haver práticas que não permitem mudança gradiente e frequente no sistema emergente rumo a uma representação rica do PB, mas, sim, rumo a um sistema de competidores constituído de itens fracos e que inibem categorização consistente.

\section{Considerações finais}

A técnica Cloze, para além da quantificação de erros e acertos, usada de forma adaptada para esta pesquisa, ofereceu informações que permitiram identificação de evidências sobre construções nominais, para uma introdutória caracterização do conhecimento linguístico de surdos adultos que chegam à universidade. A tipologia de divergências apresentada neste artigo contribui para uma atuação docente mais consciente sobre alguns aspectos morfossintáticos do $\mathrm{PB}$, necessários ao desenvolvimento das habilidades de leitura e escrita. Esse tipo de informação diagnóstica parece ser 


\section{REVISTA DA ABRALIN}

revelador aos professores que atuam em todos os níveis de ensino, na medida em que oferece indícios da representação do PB alcançada pelo aprendiz durante o processo de ensino/aprendizagem.

A análise geral dos dois instrumentos indicou que a constituição das palavras que compõem os textos parece desbotada à maioria dos informantes surdos de primeira geração integrantes dos grupos A (com privação linguística). Essa indicação considerou a baixa identificação combinatória entre formas e significados/funções que desempenham as palavras colocadas nas construções usadas nos dois textos. Sugerimos que o PB emerja com uma fraca complexidade morfossintática, em consequência de oferta de amostras de input inconsistentes para reconhecimento de padrões de uso. Há ainda que se considerar o efeito do fenômeno da transferência de um tipo de padrão construcional que envolve polifuncionamento de itens lexicais em LIBRAS, no conhecimento emergente do PB. É desejável, sem dúvida, que o experimento avaliativo seja replicado a mais aprendizes surdos e que os resultados sejam publicados.

Em uma bem fundamentada didática aquisicional, há um poderoso e necessário trabalho com percepção do input em atividades de leitura, que faz evoluir o metabolismo linguístico para uma variedade que se espera sempre mutante em direção a uma representação cognitiva com fortes conexões para uma necessária autonomia dos surdos no uso do PB.

\section{REFERÊNCIAS}

ACESSIBILIDADE BRASIL. Dicionário da língua brasileira de sinais. Disponível em: http://www.acessibilidadebrasil.org.br/libras/Acesso em: 20 de abril de 2017.

ABRAHAM, Roberta G.; CHAPELLE, Carol A. The meaning of cloze test scores: An item difficulty perspective. The Modern Language Journal, v. 76, n. 4, p. 468-479, 1992. https://doi.org/10.1111/j.1540-4781.1992.tb05394.x.

ABREU, Katia. N. M. de.; GARCIA, Daniela C.; HORA, Katharine F. P.N.A. da; SOUZA, C. R. O teste de Cloze como instrumento de medida da proficiência em leitura: fatores linguísticos e não linguísticos. Revista de Estudos da Linguagem, Belo Horizonte, v.25, n.3, p. 1767-1799, 2017. http://dx.doi.org/10.17851/2237-2083.25.3.1767-1799.

ANDREWS, Jean F.; BYRNE, Andrew; CLARK, M. Diane. Deaf scholars on reading: A historical review of 40 years of dissertation research (1973-2013): Implications for research and practice. American annals of the deaf, v. 159, n. 5, p. 393-418, 2015.

BARLOW, Michael; KEMMER, Suzanne. Usage Based Models of Language. The University Chicago Press, 2000. BATES, Elizabeth; MACWHINNEY, Brian. Second-language acquisition from a functionalist perspective: Pragmatic, semantic, and perceptual strategies. Annals of the New York Academy of Sciences, v. 379, n. 1, p. 190214, 1981. https://doi.org/10.1111/j.1749-6632.1981.tb42009.x

BOCHNER, Joseph H.; ALBERTINI, John A. Language varieties in the deaf population and their acquisition by children and adults. STRONG, M. (Ed.). Language Learning and Deafness (Cambridge Applied Linguistics). Cambridge: Cambridge University. p. 3-48, 1988. https://doi.org/10.1017/CBO9781139524483. BYBEE, Joan. Língua, Uso e Cognição. Tradução de Maria Angélica Furtado da Cunha. São Paulo: Editora Cortez, 2016. 


\section{REVISTA DA ABRALIN}

CAPOVILLA, Fernando. RAPHAEL, Walkyria D.; MAURICIO, Aline Cristina L. Novo Deit-Libras: Dicionário enciclopédico ilustrado trilíngue da língua de sinais brasileira (Libras) baseado em Linguística e Neurociências Cognitivas. 2009

CASTILHO, Ataliba T. de. Nova gramática do português brasileiro. São Paulo: Contexto, 2010.

CLARKE, Mark A.; BURDELL, Linda. Shades of meaning: syntactic and semantic parameters of cloze test responses. BROWN, H.D., YORIO, C. A., CRYMES, R.H. (Orgs.). Teaching and learning; trends in research and practice (On TESOL '77). Washington: TESOL, 1977.

COSTA, Marilia. U. C. L. M.; SOARES, Lia A. A.; GARCIA, Daniela Cid de; ABREU, Katia. N.M. As guerras do ensino da leitura: um olhar a partir da epistemologia surda. Revista Espaço, v. 53, p. 127-151, 2020.

http://dx.doi.org/10.20395/re.v0i53.651.

FREITAS JR, Roberto; SOARES, Lia Abrantes Antunes; NASCIMENTO, João Paulo da Silva; XAVIER, Hosana Sheila da Silva Rosa. Será um grande de aprendizado: uma análise descritiva dos aspectos linguísticos da escrita de surdos em PBL2 - Interfaces entre textualidade, uso e cognição no estado de interlíngua. Rio de Janeiro. Pensares em revista, v. 01, p. 0729, 2018. https://doi.org/10.12957/pr.2018.33200.

GASS, Susan M.; SELINKER, Larry. Second Language Acquisition: an introductory Course. Hillsdale; Hover; Londres: Lawrence Erlbaum, 2001.

GOLDBERG, Adelle. Constructions at work: the nature of generalization in language. Cambridge: University Press, 2006.

GOLDBERG, Adelle. Explain me this: creativity, competition, and the partial productivity of constructions. New Jersey: Princeton University Press, 2019.

HILPERT, Martin. Construction Grammar and its application to English. Edinburgh: Edinburgh University Press, 2019.

HÖDER, Steffen. Grammar is community-specific: Background and basic concepts of Diasystematic Construction Grammar. In Hans C. Boas \& Steffen Höder (eds.), Constructions in contact. Constructional perspectives on contact phenomena in Germanic languages (Constructional Approaches to Language 24), 37-70. Amsterdam: Benjamins, 2018.

JOLY, Maria Cristina R. A. et al. Avaliação da compreensão de leitura pelo Sistema Orientado de Cloze (SOC). Fractal: Revista de Psicologia, v. 26, n. 1, p. 223-242, jan./abr. 2014. Universidade Federal Fluminense. https://doi.org/10.1590/S1984-02922014000100016.

LAUFER, Batia. What's in a word that makes or hard or easy. In: MCCARTHY, M.; SCHMIDT, N. (Ed.). Vocabulary: description, acquisition and pedagogy. Cambridge: Cambridge University Press, 1997. p.140-155.

NASCIMENTO, João Paulo da S.; SOARES, Lia Abrantes A.; FREITAS JR, Roberto. Os bastidores da escrita: análise cognitivo-funcional de processos cognitivos operantes na aquisição de PBL2 por surdos bilíngues. Revista Diálogos, 2019.

NEWELL, Allen. Unified theories of cognition. Harvard: Harvard University Press, 1990

SANTOS, Acácia A. A., PRIMI, Ricardo. TAXA, Fernanda. VENDRAMINI, Claudete M. O teste de Cloze na avaliação da compreensão em leitura. Psicologia - Reflexão e Crítica, v. 15, n. 3, p. 549-560, 2002.

https://doi.org/10.1590/S0102- 


\section{REVISTA DA ABRALIN}

SANTOS, Acácia A. Angeli; MONTEIRO, Rebecca M. Validade do Cloze enquanto técnica de avaliação da compreensão de leitura. Estudos Interdisciplinares em Psicologia, v. 7, n. 2, p. 86-100, 2016. 10.5433/22366407.2016v7n2p86.

SOARES, Lia Abrantes Antunes. A emergência de um sistema de competidores: um estudo cognitivo-funcional dos processos mentais subjacentes ao desenvolvimento do PBL2 em surdos universitários. Tese de Doutorado em Língua Portuguesa. Instituto de Letras. Universidade do Estado do Rio de Janeiro, 2018.

SOARES, Lia Abrantes Antunes. Português e Libras: distorções e supergeneralizações. In: FREITAS JR, Roberto de (Orgs); SOARES, Lia Abrantes Antunes (Orgs); NASCIMENTO, João Paulo da Silva (Orgs). Aprendizes surdos e escrita em L2: reflexões teóricas e práticas. Rio de Janeiro: Faculdade de Letras. 1ª Edição. 2020.

SOARES, Lia Abrantes Antunes; NASCIMENTO, João Paulo da Silva. Evidências sobre a representação cognitiva de construções funcionais do PB em crianças e adultos surdos. Revista Linguíftica, v. 16, n. 2, p. 135-154, 2020. https://doi.org/10.31513/linguistica.2020.v16n2a33881.

TAYLOR, Wilson. L. Cloze procedure: a new tool for measuring readability. Journalism Quarterly, Questia Trusted Online Research, v. 30, p. 415-433, 1953.

TOMASELLO, Michael. Origens culturais da aquisição do conhecimento humano. Martins Fontes, 2003. 